\title{
Aspectos do mecanismo de ação do amônio glufosinato: culturas resistentes e resistência de plantas daninhas ${ }^{1}$
}

\section{Aspects of the mechanism of action of the ammonium glufosinate: resistant crops \\ and resistance of weeds}

\section{Caio Augusto De Castro Grossi Brunharo ${ }^{2}$; Pedro Jacob Christoffoleti ${ }^{3}$; Marcelo Nicolai $^{4}$}

Resumo - Com o advento de culturas geneticamente modificadas para a tolerância ao herbicida não-seletivo amônio glufosinato no Brasil, associado à sua importância como herbicida alternativo às áreas infestadas por plantas daninhas resistentes ao glyphosate, o conhecimento de certos aspectos sobre seu mecanismo de ação, particularidades da molécula e manejo consciente tornamse necessários. Nesse sentido, a presente revisão de literatura foi realizada na tentativa de abranger, à luz do atual conhecimento, os conceitos sobre a bioquímica envolvida no mecanismo de ação desse herbicida, sua dinâmica de entrada na célula vegetal, sua utilização em culturas geneticamente modificadas e seu uso consciente, com a intensão de prolongar ao máximo possível essa ferramenta do sistema de produção de alimentos.

Palavras-chaves: gene pat, gene bar, planta daninha resistente, OGM, mecanismo de ação

Abstract - With the release of genetically modified organisms for tolerance of the non-selective herbicide ammonium-glufosinate in Brazil, along with its importance as an alternative herbicide to glyphosate-resistant weed, the knowledge of certain aspects related to its mode of action, chemical features and rational management become necessary. In this context, the present literature review was idealized in an attempt to cover, in the light of the current knowledge, some concepts about the biochemistry related to the mode of action of this herbicide, its uptake dynamics, its usage in GM plants and its rational management, with the purpose of making it last as long as possible in the agriculture systems.

Keywords: herbicide-resistant weed, pat gene, bar gene, GMO, mode of action

\section{Introdução}

A assimilação do nitrogênio constitui, exceto quando comparado à assimilação do $\mathrm{CO}_{2}$, a função mais importante da célula de uma planta. Nesse contexto, a glutamina sintetase é uma enzima chave na assimilação de amônia nas células. $\mathrm{O}$ gene que codifica a glutamina sintetase é considerado um dos mais antigos quando se baseia em todas as formas de vida ao longo da evolução (Kumada et al., 1993).

Amonium - DL - homoalanin -4-yl(methyl) phosphinate, nome comum do amônio glufosinato, é um herbicida amplamente

\footnotetext{
${ }^{1}$ Recebido para publicação em 13/12/2014 e aceito em 25/05/2015.

${ }^{2}$ Doutorando na University of California. Davis, Califórnia, Estados Unidos. cabrunharo@ucdavis.edu (*autor para correspondência).

${ }^{3}$ Professor Associado Nível 3, Departamento de Produção Vegetal, Escola Superior de Agricultura "Luiz de Queiroz", Universidade de São Paulo. Piracicaba, São Paulo, Brasil.

${ }^{4}$ Pesquisador, Dr., Agrocon, Assessoria Agronômica. Piracicaba, São Paulo, Brasil.
} 
utilizado na agricultura em escala mundial, em função tanto da alta eficácia quanto do amplo espectro de controle de plantas daninhas. Possui duas formas, a ativa, que tem ação herbicida (LPhosphinothricin) e a inativa (DPhosphinothricin). Foi inicialmente isolado de Streptomyces viridochromogenes (Bayer et al., 1972). A glutamina sintetase, considerada a via de assimilação do nitrogênio, é a enzima alvo de inibição dessa rota, uma vez que ela pode ser inibida utilizando-se concentrações baixíssimas de glufosinato (Lea \& Ridley, 1989; Kruckberg et al., 1989). Plantas tratadas com o amônio glufosinato mostram rápido acúmulo de amônia, associado à destruição de cloroplastos, redução dos níveis de fotossíntese e redução na produção de aminoácidos, resultando na inibição da fotossíntese e morte celular (Sauer et al., 1987). Os principais sintomas que as plantas mostram após a aplicação de amônio glufosinato são: rápida clorose do tecido tratado, seguido de necrose e morte das plantas após poucos dias.

O conhecimento da utilização de plantas tolerantes ao amônio glufosinato é relativamente mais antigo do que se imagina. Wohlleben et al. (1988) introduziram o gene pat em Nicotiana tabacum com a utilização de Agrobacterium tumefaciens, obtendo uma planta geneticamente modificada para a tolerância ao amônio glufosinato. O gene pat (Phosphinothricin $N$-acetiltransferase) codifica a N-Acetiltransferase, responsável pela inativação do amônio glufosinato (LPhosphinothricin) por meio de uma reação de acetilação (Murakami et al., 1986), impedindo que o herbicida atinja o sítio de ação (Wehrmann et al., 1996). Desde então, culturas geneticamente modificadas para a tolerância ao amônio glufosinato vem surgindo e sendo amplamente adotadas.

A resistência de plantas daninhas a herbicidas é definida como a capacidade natural e herdável de determinados biótipos, dentro de uma população, de sobreviver e se reproduzir após a exposição a doses de herbicidas que seriam letais a indivíduos normais (suscetíveis) da mesma espécie (Christoffoleti \& LópezOvejero, 2008). Apesar do amônio glufosinato ser um herbicida não seletivo, existem relatos descrevendo diferentes respostas de suscetibilidade de plantas daninhas, onde as causas podem ser explicadas por diferenças na translocação, absorção e metabolismo (Everman et al., 2009a; Skora-Neto et al., 2000; Pline et al., 1999). Entretanto, até o momento apenas duas espécies de plantas daninhas foram reportadas como resistentes ao amônio glufosinato: capim-pé-de-galinha (Eleusine indica L.) (Jalaludin et al., 2010a; Seng et al., 2010) e azevém (Lolium perenne L. ssp. multiflorum) (Avila-Garcia et al., 2012).

O surgimento de biótipos resistentes ocorre, com maior frequência, em áreas onde há uso repetido de herbicidas de um mesmo grupo químico ou pertencentes a diferentes grupos químicos, mas com o mesmo mecanismo de ação (Duke \& Powles, 2008; Powles \& Yu, 2010). De modo geral, para evitar o surgimento de espécies resistentes em uma área agrícola é necessária redução da pressão de seleção na população por meio de práticas agrícolas como planejamento do sistema de produção, rotação de culturas, rotação de herbicidas, associação entre ingredientes ativos de diferentes mecanismos de ação, diferentes estratégias de manejo envolvendo aplicações de herbicidas pré e pós-emergentes, sendo que tudo isso de nada adianta se não forem práticas coletivas e em conjunto com os agricultores de uma região, uma vez as espécies de plantas daninhas possuem sementes que são dispersadas por muitos quilômetros, seja naturalmente pelo vento ou chuva, seja pela influência do homem e seus implementos agrícolas (Christoffoleti et al., 2014 a).

Sendo assim, considerando a importância do herbicida amônio glufosinato para a agricultura, a evolução do uso de culturas transgênicas resistentes e o potencial de seleção de plantas daninhas resistentes, foi desenvolvida esta revisão de literatura. O objetivo principal é informar e alertar os usuários da tecnologia de 
culturas resistentes ao glufosinato sobre a necessidade de uso racional da mesma, sempre utilizando de forma integrada com outras práticas de manejo.

\section{Fixação do Nitrogênio e Mecanismo de Ação do Amônio Glufosinato}

$\mathrm{O}$ nitrogênio é um dos elementos mais abundantes nas plantas, compondo aminoácidos, ácidos nucleicos e inúmeros outras substâncias indispensáveis para o seu funcionamento adequado. Em condições naturais, o nitrogênio é um elemento cuja disponibilidade é limitada. Diante disso, ao longo da evolução, as plantas encontraram mecanismos para perder a menor quantidade possível de nitrogênio. Para isso, a amônia liberado em altas concentrações na rota metabólica da foto-oxidação da glicina deve ser de alguma forma utilizada. A glutamina sintetase é uma importante enzima na assimilação do nitrogênio presente nos estromas dos cloroplastos, fotorrespiração e balanço de carbono em plantas. A localização da glutamina sintetase pode ser classificada em dois grupos: a isoforma citossólica(GS1) e a isoforma plastídica (GS2) (Unno et al., 2006).

No começo dos anos 70, a glutamina sintetase era considerada limitada a um número pequeno de plantas superiores, presentes apenas nas raízes e órgãos fotossinteticamente ativos (Kanamori \& Matusmoto, 1972). Pouco tempo depois, foi descoberta a existência de duas formas de glutamina sintetase: citossólica e cloroplástica (Guiz et al., 1979) na qual a cloroplástica, por exemplo, possui peso molecular de 45000 daltons (Hirel et al., 1984), e possui a forma de uma roseta hexagonal (Yamashita et al., 1989). McNally et al. (1993) classificou as plantas superiores em três grupos quanto à existência da glutamina sintetase. $\mathrm{O}$ primeiro grupo possui apenas a forma GS2 como tomate (Solanum licopersicum L.), tabaco (Nicotiana tabacum L.) e espinafre (Spinacia oleracea L.). O segundo grupo é composto por espécies de aveia (Avena sativa L.), cevada
(Hordeum vulgare L.) e arroz (Oryza sativa L.), que possuem predominantemente a isoforma GS2 (entre 82-95\%). Por fim, o terceiro grupo é composto por espécies de sorgo (Sorghum bicolor Pers.), milho (Zea mays L.) e capimarroz (Echinochloa crus-galli L.) e possuem predominantemente a isoforma GS1, em uma proporção de 2:1.

Esta enzima catalisa a transferência do íon amônia $\left(\mathrm{NH}_{3}\right)$ para o grupo $\delta$-carboxílico do glutamato para formar a glutamina. Essa reação acontece com a transformação de uma molécula de ATP para ADP e P. O nitrogênio fixado na forma de amida na glutamina é transferido, por uma reação de redução de amina, a $\alpha$ ketoglutarato. Esta última reação é catalisada pela glutamato sintetase, e duas moléculas de glutamato são formadas (Meek \& Villafranca, 1980), como é possível visualizar na figura 1. A partir dessa rota metabólica, o glutamato funciona como uma fonte de amônio em diversas outras rotas metabólicas como a produção de aspartato (Givan, 1980) asparagina (Lea, 1993), além de ter a função de desintoxicação da amônia produzida a partir da redução do nitrato.

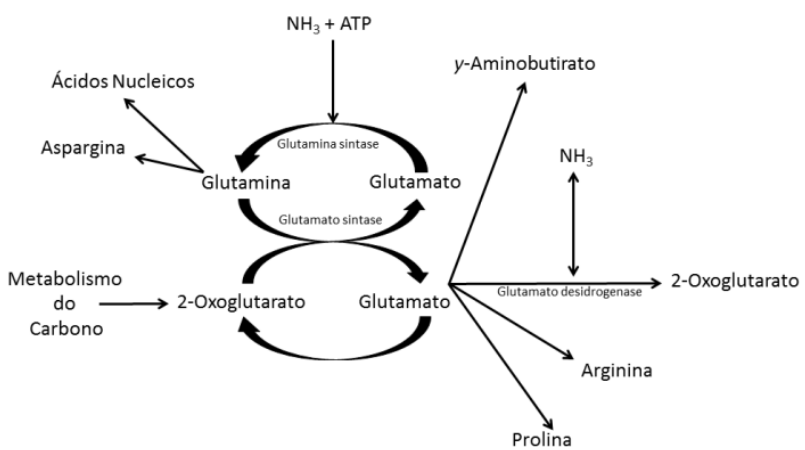

Figura 1. Rota metabólica simplificada do glutamato (Adaptado de Forde \& Lea, 2007).

O ingrediente ativo amônio glufosinato é um substrato análogo ao glutamato, inibindo a enzima glutamina sintetase (GS; E. C. 6.3.1.2), uma enzima central no metabolismo da amônia em plantas (Manderscheid \& Wild, 1986). Ele compete pelos locais em que o glutamato se liga 
à glutamina sintetase onde, uma vez que o glufosinato tem sucesso, a ligação se torna irreversível (Logusch et al., 1991). A irreversível ligação entre o amônio glufosinato e a glutamina sintetase resulta em rápida acumulação, em níveis tóxicos, de amônia dentro da célula (Kishore \& Shah, 1988; Tachibana et al., 1986a).

Apesar de a alta concentração de amônia parecer ser a principal causa da morte celular, Krieg et al. (1990) submeteram células em meio de cultura de Medicago sativa a $400 \mathrm{mM}$ de nitrato de amônio, nível 10 vezes maior que o normalmente utilizado, sem inibição do crescimento e desenvolvimento das células estudadas, concluindo que o alto acúmulo de amônia causado pelo glufosinato não é a causa primária da morte celular. Efeitos como inibição da síntese de proteínas (especialmente a proteína $\mathrm{Qb}$ envolvida no transporte de elétrons no fotossistema), níveis tóxicos de glioxilato, insuficiente produção de glutamato, aspartato e alanina, e insuficiente regeneração de compostos intermediários do ciclo C3 são os principais responsáveis pela morte celular (Lea, 1991).

Estudos apontam diferenças entre suscetibilidade de plantas ao amônio glufosinato, tanto por diferenças de movimento (absorção e translocação) quanto por metabolismo (Everman et al., 2009b; Steckel et al., 1997; Skora-Neto et al., 2000). Na maioria das espécies em que a absorção do glufosinato foi estudada, o pico de absorção é atingido após 24 horas de sua aplicação (Sellers et al., 2004). Devido à similaridade do amônio glufosinato com aminoácidos como o glutamato, acredita-se que sua absorção seja realizada por meio de cotransportadores de prótons (Ullrich et al., 1990). Sua ação é dependente de luz em diversas plantas daninhas (Wild \& Manderscheid, 1984; Köcher, 1983).

Apesar de ter propriedades físicoquímicas para ter mobilidade no floema das plantas $(\mathrm{pKa}=<2 ; 2.9 ; 9.8$, e $\log$ Kow $\approx 3,9)$ (Kleier et al., 1988; Hsu \& Kleier, 1990), a translocação do glufosinato é muito pequena. Porém é possível identificar diferença de translocação entre as plantas consideradas mais tolerantes e as mais suscetíveis, da qual as últimas possuem maior translocação (Shelp et al., 1992). Existem diversas teorias para explicar a baixa mobilidade do glufosinato. (Beriault et al., 1999; Sauer et al., 1987; Zeigler \& Wild, 1989). Uma delas pode ser devido à imediata inibição da glutamina sintetase, culminando com acúmulo de amônia nas células e diminuição de glutamina. $\mathrm{O}$ acúmulo de amônia causa ruptura das membranas celulares, causando a morte dos tecidos antes mesmo de o glufosinato ser transportado para o floema (Tachibana et al, 1986b).

Berialt et al. (1999), estudando colza (Brassica napus) suscetível e resistente (através de transformação), concluíram que a mistura racêmica do amônio glufosinato é pouco translocável (DL-glufosinate), porém com diferenças estatísticas entre as plantas suscetíveis e resistentes. O D-glufosinato (sem efeito herbicida) foi mais translocado que a mistura racêmica e seu principal metabólito $(\mathrm{N}$ Aceyl-L-Glufosinate) possui ampla translocação no floema com acumulação nas gemas.

\section{Culturas Tolerantes ao Amônio Glufosinato}

A glutamina sintetase é uma enzima produzida no núcleo das células fotossintetizantes e que catalisa a conversão do glutamato a glutamina, com a assimilação de amônia no citoplasma e plastídios (Vaughn \& Duke, 1991). O amônio glufosinato é composto por uma mistura racêmica, e seu isômero-L é o inibidor da glumina sintetase, enquanto que o isômero-D não tem atividade como herbicida (Ruhland et al., 2004). A estrutura molecular do L-glufosinate é muito semelhante àquela do Lglutamate, e a inibição dessa última é feita de forma competitiva (Reade \& Cobb, 2002).

A entrada do amônio glufosinato nas plantas é realizada exclusivamente por tecidos 
verdes e raízes, enquanto que as partes lignificadas não funcionam como entrada do herbicida. Entretanto, de forma geral, o amônio glufosinato era amplamente utilizado em culturas perenes, operações de dessecação e em jato-dirigido. Contudo, após a introdução de culturas tolerantes a este herbicida, sua utilização se tornou amplamente adotada, ampliando seu leque de utilidades.

O gene bar, clonado a partir de Streptomyces hygroscopicus, foi inicialmente inserido em tabaco por De Block et al. (1987), com completa tolerância ao amônio glufosinato. Este gene codifica a enzima PAT, que converte o amônio glufosinato a uma forma acetilada sem ação tóxica (Figura 2). De forma similar ao gene bar, o gene pat, isolado de Streptomyces viridochromogenes Tü494 (Strauch et al., 1988), codifica a enzima phophinothricin-Nacetyl-transferase, que também catalisa uma reação de acetilação do $\mathrm{NH}_{2}$ do amônio glufosinato, inativando-o, resultando na mesma forma inativa da Figura 2. Ambos os genes são altamente homólogos (Vasil, 1996) e são estruturalmente iguais, funcionalmente equivalentes e tem desempenho comparável em plantas transgênicas e, por fim, a enzima que é codificada por estes genes, a PAT, é também similar em ambos os casos (Wehrmann et al., 1996).

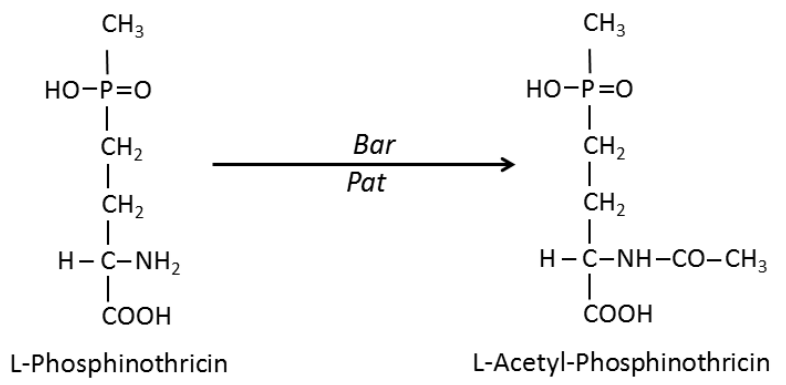

Figura 2. Interação entre PAT e glufosinato em culturas tolerantes.

Culturas tolerantes a herbicidas tiveram benefícios econômicos instantâneos. Por exemplo, Brookes \& Barfoot (2014) estimam que a utilização de soja tolerante a herbicidas trouxe $38 \%$ de economia aos agricultores que a adotaram, principalmente devido ao melhor manejo das plantas daninhas e redução de custos operacionais $(62 \%)$.

Além dos benefícios econômicos, as culturas tolerantes a herbicidas também trazem facilidade de manejo, eficácia, menor impacto ambiental e maior segurança sanitária. Em algodão, por exemplo, Christoffoleti et al. (2014b) consideram que a utilização de variedades tolerantes ao amônio glufosinato proporcione ao produtor mais opções de estratégias de controle de plantas daninhas. A redução no revolvimento do solo e a possibilidade de implantação do plantio direto permite uma ótima conservação do solo quando comparada com o plantio convencional, além de aumentar o sequestro de carbono, tanto pela redução da emissão de carbono pelo solo, quanto pela menor necessidade de uso de máquinas agrícolas (Barfoot \& Brookes, 2014).

A segurança de aplicação de herbicidas em culturas tolerantes também é um ponto que deve ser levado em consideração na escolha do cultivar. Em cultivares convencionais, a utilização de herbicidas não-seletivos é limitada, e encontrar escapes de plantas daninhas na entrelinha não é incomum, devido a motivos ligados à escolha errada de ingrediente ativo para o controle das plantas daninhas presentes na área, ao "efeito guarda-chuva" ou ao solo mal preparado no caso de préemergentes. O uso de herbicidas pósemergentes de amplo espectro com seletividade à cultura por meio de transgenia caracteriza-se como uma ferramenta muito útil em situações como as acima descritas.

Quanto à abrangência de utilização e benefício de culturas geneticamente melhoradas, existem argumentos de que estas apenas atingem grandes produtores, e pequenos fazendeiros são prejudicados. Carpenter (2010) conclui que a adoção de culturas tolerantes a herbicidas aumentou a produtividade nos países 
desenvolvidos em $7 \%$, e em $21 \%$ nos países subdesenvolvidos.

Entre os anos de 1996 a 2011, a quantidade de herbicida utilizada em milho, algodão, canola e soja tolerantes a herbicidas nos Estados Unidos era 204 milhões de quilos de ingrediente ativo. Quantidade menor que em período semelhante antes das culturas geneticamente modificadas para tolerância a herbicidas e similar à quantidade reduzida na aplicação de inseticidas (Brookes \& Barfoot, 2011).

À parte dos inúmeros benefícios trazidos pelas culturas tolerantes a herbicidas, este sucesso gerou desestímulo ao desenvolvimento de novas moléculas por parte das empresas nos últimos 20 anos (Duke, 2012), uma vez que grande parcela do mercado de químicos foi preenchida por poucas moléculas. Além do mais, o mesmo sucesso obtido pelas culturas tolerantes a herbicidas trouxe problemas como a utilização exclusiva de um único ingrediente ativo no sistema, elevando a pressão de seleção sobre as plantas daninhas e selecionando biótipos resistentes.

\section{Mecanismos de Resistência de Plantas Daninhas ao Amônio Glufosinato}

Segundo Heap (2014), existem 437 relatos registrados de plantas daninhas resistentes em 238 diferentes espécies, sendo que o número de casos tem aumentado a cada ano. Destas, 130 são eudicotiledôneas e 100 são monocotiledôneas, e já foram relatados casos de resistência a 22 dos 25 mecanismos de ação disponíveis no mercado. Até o momento foram reportadas a presença de plantas daninhas resistentes em 66 diferentes culturas em 65 países, onde Estados Unidos da América vem em primeiro lugar (145) seguidos por Austrália (70), Canadá (60) e França (35). O Brasil se encontra na oitava posição, com 33 casos, com biótipos resistentes aos herbicidas inibidores da ALS, ACCase, EPSPs, PPO, FSII e Auxinas sintéticas.
O capim-pé-de-galinha (Eleusine indica (L.) Gaertn.) é considerado uma das piores plantas daninhas do mundo não só pela sua capacidade competitiva com as plantas cultivadas, mas também pela sua alta taxa de fecundação e plasticidade a diferentes ambientes (Ismali et al., 2002). Seu controle vem se tornando cada vez mais difícil devido à seleção natural de biótipos resistentes a diversos herbicidas como a trifluralin (Vaughn et al., 1990), glyphosate (Lee \& Ngim, 2000), paraquat (Itoh et al., 1990), fluazifop-p-butil (Marshall et al., 1993), sethoxydim e fenoxaprop (Vidal et al., 2006).

Recentemente, biótipo de capim-pé-degalinha foi identificado na Malásia com resistência múltipla ao paraquat e amônio glufosinato (Seng et al., 2010b). De acordo com os autores, a utilização repetitiva desses dois herbicidas vem acontecendo, tanto em combinação quanto isoladamente, pelo menos seis vezes ao ano desde 2006. Os mecanismos que conferem resistência a esse biótipo ainda não foram esclarecidos, apesar de este biótipo necessitar ser submetido a 3,4 vezes mais herbicida para ter seu crescimento inibido em $50 \%$ quando comparado ao biótipo suscetível $\left(\mathrm{GR}_{50 \mathrm{r}} / \mathrm{GR}_{50 \mathrm{~s}}\right)$ em condições de casa-devegetação, sendo a dose recomendada naquele país de $450 \mathrm{~g}$ i.a.ha ${ }^{-1}$.

$\mathrm{O}$ azevém (Lolium perenne L. ssp. multiflorum) é uma planta daninha que se espalhou pelo mundo por ter bom desenvolvimento em regiões temperadas como gramínea para alimentação animal. Sua frequente presença em pomares nos Estados Unidos da América do Norte, associada com a possibilidade de utilização de herbicidas nãoseletivos em culturas perenes, faz com que a utilização repetitiva de amônio glufosinato, glyphosate, clethodim e paraquat, por exemplo, seja comum (Hoskins et al., 2005). A princípio, no estado de Oregon, a frequente utilização de glyphosate como produto primário para $\mathrm{o}$ controle do azevém culminou com a seleção de sete populações resistentes, nas quais estima-se 
que tenha havido a utilização desse herbicida por 10 anos consecutivos, com duas a três aplicações anuais (Perez-Jones et al., 2005; Avila-Garcia \& Mallory-Smith, 2011).

Avila-Garcia \& Mallory-Smith (2011) calcularam que a quantidade de amônio glufosinato necessária para a redução em $50 \%$ do crescimento do azevém foi em média de 2,4 vezes maior para o biótipo resistente do que para o suscetível (FR $\left.{ }_{50}\right)$. Os autores, em uma tentativa de melhor caracterização do problema, também estudaram o acúmulo de amônia e atividade da glutamina sintetase. O biótipo suscetível acumulou até 2,6 vezes mais amônia do que o biótipo resistente, fato que demonstra que o amônio glufosinato está ativamente atingindo seu sítio de ação e expressando seu efeito. Para a confirmação desta última afirmativa, a inibição da glutamina sintetase foi maior nos biótipos suscetíveis e estatisticamente menores nos biótipos resistentes. Os autores ainda lançam a hipótese de que o mecanismo de resistência ao amônio glufosinato nas populações estudadas é devido à diferença de translocação, uma vez que os biótipos também apresentam resistência ao glyphosate e as populações resistentes ao amônio glufosinato, na área em que estas foram coletados, nunca haviam anteriormente sido submetidos a aplicações de amônio glufosinato. Avila-Garcia et al. (2012), continuando sua pesquisa, encontraram mutação no gene que codifica a GS2, onde foi identificada a substituição de um ácido aspártico por uma asparagina na posição 171 no biótipo resistente.

\section{Amônio Glufosinato e o Manejo de Plantas Daninhas Resistentes}

O objetivo do manejo de plantas daninhas nas culturas é minimizar as perdas devido à interferência, beneficiar as condições de colheita, reduzir o incremento do banco de sementes de plantas daninhas, evitar a seleção de biótipos de plantas daninhas resistentes a herbicidas, com a menor contaminação ambiental possível e maior lucratividade.
Pesquisas apontam que o manejo no sistema de produção pode inferir no aparecimento de biótipos resistentes devido à alteração no sítio de ação do herbicida ou na quantidade que atinge o sítio de ação. $\mathrm{O}$ uso de dosagens de herbicidas superiores àquelas recomendadas em rótulo pode selecionar biótipos com resistência por alteração no sítio de ação do herbicida e doses abaixo da recomendada tendem a selecionar biótipos com a habilidade de diminuir a quantidade de herbicida que atinge o sítio de ação (Gardner et al., 1998).

O amônio glufosinato, não apenas no Brasil, mas no mundo todo, vem sendo utilizado e empregado como um herbicida não-seletivo pós-emergente alternativo ao glyphosate, principalmente quando estabelecido o manejo reativo (após o aparecimento da resistência). No Brasil, já foram identificados biótipos de buva [Conyza bonariensis (L.) Cronquist; Conyza canadensis (L.) Cronquist] (Moreira et al., 2007; Vargas et al., 2007), azevém (Lolium multiflorum Lam.) (Vargas et al., 2004), capimamargoso [Digitaria insularis (L.) Fedde] (Melo, 2012), buva [Conyza sumatrensis (L.) Cronquist] (Santos et al., 2012) e capim-branco [(Chloris polydactyla (L.) Sw.] (Brunharo, 2014) como sendo resistentes ao glyphosate.

Tendo como exemplo o ocorrido na Malásia (Seng et al., 2010b), em que primeiramente foi constatada a presença de biótipos resistentes ao glyphosate, e depois de algum tempo foi constatada a resistência ao amônio glufosinato, o manejo integrado, associando-se herbicidas de diferentes mecanismos de ação, deve ser implementado dentro de um manejo preventivo de aparecimento da resistência (Buhler, 2002).

Nos Estados Unidos da América, a ocorrência de biótipos resistentes de buva (Conyza canadensis) resulta no aumento do custo de produção da soja em US\$ 28,42 ha ${ }^{-1}$ (Mueller et al., 2005). Já para controlar o Amaranthus rudis resistente ao glyphosate, o aumento do custo de produção da soja pode chegar a US\$ 48,00 ha ${ }^{-1}$ em Missouri (Legleiter 
et al., 2009). Para ambos os casos anteriormente citados, uma das alternativas de manejo pósemergente que vem sendo utilizada é a utilização do amônio glufosinato. As pesquisas quanto ao custo de controle de plantas daninhas resistentes ao amônio glufosinato são limitados, mas é impossível de se visualizar outro cenário que não seja o aumento do custo de produção.

A integração entre herbicidas préemergentes e pós-emergentes pode resultar em controle mais efetivo das plantas daninhas do que apenas uma aplicação em pós ou apenas uma aplicação em pré-emergência. Jones et al. (2001) chegaram à conclusão de que a aplicação da atrazina em milho resistente a amônio glufosinato na semeadura e amônio glufosinato complementando o controle das plantas escapes em pós-emergência resultou em controle mais efetivo (maior que $94 \%$ de controle visual das plantas daninhas do que apenas a aplicação de amônio glufosinato em pós-emergência. Johnson et al. (2000) também concluíram que a aplicação de um herbicida pré-emergente, complementado posteriormente com a aplicação de glyphosate em pós-emergência resultou em maior produtividade e menor presença de plantas daninhas, comparado com a aplicação apenas de glyphosate na pós-emergência.

No Brasil, trabalhos envolvendo a utilização do amônio glufosinato em associação a outros herbicidas tem mostrado grande eficácia no manejo de plantas daninhas em pomares, em milho e em algodão, culturas utilizando o amônio glufosinato em aplicações de área total ou jato dirigido. Em citrus, em função do grande problema enfrentado com as infestações de buva [Conyza bonariensis (L.) Cronquist; Conyza canadensis (L.) Cronquist] resistente ao glyphosate, procedeu-se o uso do amônio glufosinato como complemento do manejo normal dos pomares. Moreira et al. (2010) estudaram esta possibilidade e concluíram que o amônio glufosinato complementava o controle da buva resistente ao glyphosate e ainda sugeriam que um préemergente devesse ser incluído no manejo para redução da pressão do banco de sementes. Ainda em citrus, Melo et al. (2012) observaram que o amônio glufosinato complementa o manejo da planta daninha capim-amargoso (Digitaria insularis) resistente ao glyphosate, quando a mesma sobrevive a aplicações de herbicidas inibidores da ACCase.

Wychen et al. (1999) estudaram o controle de plantas daninhas em milho tolerante ao amônio glufosinato, tirando interessantes conclusões: a aplicação sequencial de amônio glufosinato espaçadas entre 10 e 18 dias, atrazina complementada com amônio glufosinato em pós-emergência, s-metolachlor complementado com amônio glufosinato em pós-emergência ou então a associação entre atrazina e amônio glufosinato em pósemergência foram sempre melhores do que a aplicação isolada tanto de amônio glufosinato quanto de s-metolachlor + atrazina para o controle de ançarinha-branca (Chenopodium album), losna-do-campo (Ambrosia artemisiifolia), painço (Panicum dichotomiflorum) e benção-de-deus (Abutilon theophrastin). Além disso, os autores ainda concluem que o milho tratado com amônio glufosinato mostrou maior produtividade do que ambas as testemunhas com controle convencional e com controle manual de plantas daninhas.

No manejo de plantas daninhas em milho Herculex, ainda que não fosse uma recomendação oficial de nenhum fabricante, o uso de amônio glufosinato foi comum desde o início da comercialização destes híbridos. Estes híbridos de milho foram desenvolvidos para o controle de alguns insetos lepdopteros, porém por se utilizar o mesmo gene marcador (gene bar, clonado a partir de Streptomyces hygroscopicus) da tolerância ao amônio glufosinato, o herculex é tolerante também a este herbicida. Assim, dentro do manejo convencional de plantas daninhas em milho tornou-se possível, utilizando-se o milho Herculex, a inserção do amônio glufosinato dentro deste manejo, durante o ciclo da cultura. 
Inicialmente como complemento do programa de manejo e depois como ferramenta única (Kawaguchi et al., 2012).

Em algodão possivelmente observa-se a mais destacada utilização de amônio glufosinato no Brasil. Em função da utilização das variedades FiberMax 993, lançada em 2006 e FiberMax 910, que chegou ao mercado em 2008, o cotonicultor passou a adotar o amônio glufosinato como herbicida de manejo dentro da cultura de algodão, com sucesso enorme. O algodão é uma planta que possui um longo período de prevenção da interferência das plantas daninhas, necessitando o uso de herbicidas residuais e herbicidas pós-emergente em diferentes momentos do ciclo (Christoffoleti et al., 2014b). Como a seletividade também é muito importante na cultura do algodão, o uso do amônio glufosinato para os escapes, tanto de folhas largas como de gramíneas, aumentou, em oportunidades e doses.

Nicolai et al. (2013) estudaram diferentes programas de manejo de plantas daninhas envolvendo herbicidas residuais, glyphosate e amônio glufosinato, sendo que as melhores situações de manejo foram aquelas onde se combinou o uso de pré-emergentes e as complementações, em até três momentos distintos, de amônio glufosinato em área total, a $400 \mathrm{~g}$ i.a. ha ${ }^{-1}$. Mais recentemente foram introduzidas no mercado as variedades FM 980 GLT, FM 840 GLT e FM 913 GLT, onde a sigla GLT indica que as variedades possuem as tecnologias $\quad$ GlyTol $^{\circledR}, \quad$ LibertyLink $^{\circledR} \quad$ e TwinLink $^{\circledR}$. Isso significa que é possível o uso dos herbicidas glyphosate e amônio glufosinato em pós-emergência do algodão, em qualquer fase do desenvolvimento do mesmo. Nicolai et al. (2014) estudaram novamente diferentes programas de manejo de plantas daninhas envolvendo herbicidas residuais, glyphosate e amônio glufosinato sobre as variedades FM 980 GLT e FM 913 GLT, observando que o uso do pré-emergente continua sendo fundamental, com até três complementações em pósemergência, com o diferencial de que quando se combinou o glyphosate e o amônio glufosinato, em aplicações intercaladas, obteve-se o melhor controle para um infestação composta de folhas largas e gramíneas, sendo que uma das folhas largas era a buva [Conyza bonariensis (L.) Cronquist] resistente ao glyphosate, em alta infestação.

Umidade relativa e temperatura do ar são fatores que, no geral, influenciam a absorção de herbicidas pós-emergentes (Nalewaja \& Woznica, 1985; Anderson et al., 1993; Hull, 1970; McWhorter, 1980). Entretanto, para o controle de Amaranthus palmeri, Amaranthus retroflexus e Amaranthus rudis em condições de câmara de crescimento, Coetzer et al. (2001) não observaram diferenças com a variação da temperatura e humidade relativa. Pesquisas também apontam que a adição de sulfato de amônio à calda de pulverização auxilia tanto na absorção quanto na translocação do amônio glufosinato em algumas plantas daninhas (Maschhoff et al., 2000). Estas observações conferem mais flexibilidade para o uso de amônio glufosinato, apontando para uma ferramenta por vezes menos dependente do clima que o glyphosate, considerando-se a localização e o clima das regiões produtores de algodão, no Brasil

O uso de mais de um mecanismo de ação no controle de uma planta daninha problema é recomendado tanto para evitar o aparecimento de biótipos resistentes como para remediar a seleção já ocorrida, de modo que essa diversificação de modos de ação resulta na redução do banco de sementes do solo (Norsworthy et al., 2012). Dessa forma, com a piramidização dos eventos de transgenia para herbicidas, deve-se considerar o estudo de programas de manejo que possam associar diferentes mecanismos de ação de herbicidas, em aplicações de pré e pós-emergência, voltando-se a atenção não somente à cultura em questão na safra, mas principalmente no sistema de produção adotado na propriedade. Desta forma fim de que cada ingrediente ativo usado no manejo de plantas daninhas nas culturas 
exploradas na propriedade passa a ser tanto um investimento no sistema de produção, quanto na redução da pressão do banco de sementes de plantas daninhas de forma geral e uma ação voluntaria de prevenção da seleção de novos biótipos de plantas daninhas de forma geral.

\section{Perspectivas}

É notável na região produtora de algodão no Brasil, especialmente no estado do Mato Grosso e Oeste da Bahia, um incremento muito significativo do banco de sementes da planta daninha capim-pé-de-galinha (Eleusine indica), indicando que o manejo desta planta daninha está sendo negligenciado. Evidentemente o espectro de controle do amônio glufosinato não é específico para esta planta daninha, mas de alguma forma os sistemas de produção empregados nesta região que envolvem soja, milho e algodão estão de alguma forma selecionando esta planta daninha. Se é resistência ou sistema de manejo incorreto, o futuro nos elucidará, e acreditamos que um futuro muito próximo.

Um aspecto também notável nas áreas produtoras de algodão e de soja é o incremento de plantas daninhas da classe das folhas largas (dicotiledôneas). Este aumento da importância deve-se provavelmente à resistência ao glyphosate, principalmente da buva, e espécies de difícil controle de climas tropicais, como erva-quente, vassourinha-de-botão, dentre outras. Sendo assim, eventos múltiplos contendo a resistência ao amônio glufosinato, bem como sequência de cultivos com culturas resistentes ao amônio glufosinato ganharam mais importância sob nosso ponto de vista. Destaca-se que no futuro possivelmente teremos eventos de algodão e soja resistentes a glyphosate, amônio glufosinato e 2,4-D ou mesmo dicamba. Estes eventos provavelmente irão ajudar no manejo deste processo de seleção de folhas largas que está acontecendo nos sistemas de produção do Brasil, especialmente no Cerrado.

\section{Referências}

ANDERSON, D.M. et al. The influence of temperature and relative humidity on the efficacy of glufosinate-ammonium. Weed Research, v.33, n.2, p.139-147, 1993.

AVILA-GARCIA, W.V. et al. Target-site mutation associated with glufosinate resistance in Italian Ryegrass (Lolium perenne L. ssp. multiflorum). Pest Management Science, v.68, n.9, p.1248-1254, 2012.

AVILA-GARCIA, W.V.; MALLORY-SMITH, C. Glyphosate-resistant italian ryegrass (Lolium perenne) populations also exhibits resistance to glufosinate. Weed Science, v.59, n.3, p.305309, 2011.

BARFOOT, P.; BROOKES, G. Key global environmental impacts of genetically modified (GM) crop use 1996-2012. GM Crops Food Biotechnology Agriculture Chain, v.2, n.5, p.1-12, 2014.

BAYER, E. et al. Stoffwechselprodukte von mikroorganismen. phosphinothricin und phosphinothricin-alanyl-alanin. Helvetica Chimica Acta, v.55, n.1, p.224-239, 1972.

BERIAULT, J.N.; HORSMAN, G.P.; DEVINE, M.D. Phloem transport of D-Lglufosinate and acetyl-L-glufosinate in glufosinate-resistant and susceptible Brassica napus. Plant Physiology, v.121, n.2, p.619-627, 1999.

BROOKES, G.; BARFOOT, P. Economic imparct of GM crops: The global income and production effects 1996-2012. GM Crops Food Biotechnology Agriculture Chain, v.5, n.1, p.1-11, 2014.

BROOKES, G.; BARFOOT, P. Global impact of biotech crops: environmental effects 19962009. GM Crops Food Biotechnology Agriculture Chain, v.2, n.1, p.34-49, 2011.

BRUNHARO, C.A.C.G. Resistência da planta daninha capim-branco (Chloris polydactyla) ao herbicida glyphosate. 2014. 153 p. Dissertação 
(Mestrado em Fitotecnia) - Escola Superior de Agricultura “Luiz de Queiroz", Universidade de São Paulo, Piracicaba, 2014.

BUHLER, D.D. Challenges and opportunities for integrated weed management. Weed Science, v.50, n.3, p.273-280, 2002.

CARPENTER, J. E. Peer-reviewed surveys indicate positive impact of commercialized GM crops. Nature Biotechnology, v.28, n.4, p.319321, 2010.

CHRISTOFFOLETI, P.J. et al. Manejo de plantas daninhas na cultura do algodão. In: BORÉM, A.; FREIRE, E.C. (eds.). Algodão: do plantio à colheita. Viçosa: Editora UFV. 2014b. 312p.

CHRISTOFFOLETI, P.J.; LÓPEZ-OVEJERO, R.F. Definições e situação da resistência de plantas daninhas aos herbicidas no Brasil e no mundo. In: Aspectos de resistência de plantas daninhas a herbicidas. 3.ed. Campinas: Associação Brasileira de Ação a Resistência de Plantas aos Herbicidas, 2008. p.9-29.

CHRISTOFFOLETI, P.J.; MELO, M.S.C.M.; NICOLAI, M. Resistência de Planta Daninhas a Herbicidas. In: Aspectos da biologia e manejo de plantas daninhas. Org: MONQUERO, P.A., São Carlos, SP: RIMA Editora, 2014a. p.257283.

COETZER, E.; AL-KHATIB, K.; LAUGHIN, T.M. Glufosinate efficacy, absorption, and translocation in amaranth as affected by relative humidity and temperature. Weed Science, v.49, n.1, p.8-13, 2001.

DE BLOCK, M. et al. Engineering herbicide resistance in plants by expression of a detoxifying enzyme. The EMBO Journal, v.6, n.9, p.2513-2518, 1987.

DUKE, S.O. Why have no new herbicide mode of action appeared in recent years? Pest Management Science, v.68, n.4, p.505-512, 2012.
DUKE, S.O.; POWLES, S.B. Glyphosate: a once in a century herbicide. Pest Management Science, v.64, n.4, p.319-325, 2008.

EVERMAN, W. et al. Absorption, translocation, and metabolism of ${ }^{14} \mathrm{C}$ glufosinate in glufosinate-resistant corn, goosegrass (Eleusine indica), large crabgrass (Digitaria sanguinalis), and sicklpod (Senna obtusifolia). Weed Science, v.57, n.1, p.1-5, 2009a.

EVERMAN, W.J. et al. Absoprtion, translocation, and metabolism of glufosinate in transgenic and nontransgenic cotton, palmer amaranth (Amaranthus palmeri), and pitted morninglory (Ipomoea lacunosa). Weed Science, v.57, n.4, p.257-361, 2009 b.

FORDE, B.G.; LEA, P.J. Glutamate in plants: metabolism, regulation, and signalling. Journal of Experimental Botany, v.58, n.9, p.23392358, 2007.

GARDNER, S.N.; GRESSEL, J.; MANGEL, M. A revolving dose strategy to delay the evolution of both quantitative vs. major monogene resistances to pesticide and drugs. International Journal of Pest Management, v.44, n.1, p.161-180, 1998.

GIVAN, C.V. Aminotransferases in higher plants. In: MIFLIN, B. J. The biochemistry of Plants: Amino Acids and Derivatives. New York: Academic. p.329-357, 1980.

GUIZ, C. et al. Occurrence and influence of light on the relative proportions of two glutamine synthetase in rice leaves. Plant Science Letters, v.15, n.3, p.271-277, 1979.

HEAP, I.M. International Survey of Herbicide Resistant Weeds. Disponível em: http://www.weedscience.org, acessado em: 1 de abril de 2014.

HIREL, B. et al. Multiple subunit composition of chloroplastic glutamine synthetase of Nicotiana tabacum L. Plant Physiology, v.74, n.2, p.448-450, 1984. 
HOSKINS, A. et al. Control of Italian ryegrass (Lolium multiflorum) in winter wheat. Weed Technology, v.19, n.2, p.261-265, 2005.

HSU, F.C.; KLEIER, D.A. Phloem mobility of xenobiotics. III. Sensitivity of unified model to plant parameters and application to patented chemical hybridizing agents. Weed Science, v.38, n.3, p.315-322, 1990.

HULL, H.M. Leaf structure as related to absorption of pesticides and other compounds. In: GUNTHER, A.; GUNTHER, J.D. Residues review. New York: Springer-Verlag. 1970. p.144.

ISMALI, B.S. et al. Germination and seedling emergence of the glyphosate-resistant and susceptible biotype of Goosegrass (Eleusine indica [L.] Gaertn. Weed Biology and Management, v.2, n.4, p.177-185, 2002.

ITOH, K. et al. Paraquat resistance in Amaranthus lividus and Conyza sumatrensis in Malaysia. In: PROCEEDINGS OF THE $3^{\text {rd }}$ TROPICAL WEED SCIENCE CONFERENCE. Kuala Lumpur: MPPS, 489493, 1990.

JALALUDIN, A. et al. Preliminary findings of potentially resistant goosegrass (Eleusine indica) to glufosinate-ammonium in Malaysia. Weed Biology Management, v.10, n.4, p.256260, 2010.

JOHNSON, W.G. et al. Efficacy and economics of weed management in glyphosate-resistant corn (Zea mays). Weed Technology, v.14, n.1, p.57-65, 2000.

JONES, C.A. et al. Glufosinate combinations and row spacing for weed control in glufosinateresistant corn (Zea mays). Weed Technology, v.15, n.1, p.141-147, 2001.

KANAMORI, T.; MATSUMOTO, H. Glutamine synthetase from rice plant roots. Archives of Biochemistry and Biophysics, v.152, n.4, p.404-412, 1972.
KAWAGUCHI, I.T. et al. Avaliação da eficiência agronômica do glyphosate e do glufosinato de amônio no controle de plantas daninhas nas culturas do milho Roundup Ready® e do milho Herculex®. In: CONGRESSO BRASILEIRO DA CIÊNCIA DAS PLANTAS DANINHAS, 28. Campo Grande, MS. 2012. Resumos. Campo Grande: SBCPD, p.527-532, 2012.

KISHORE, G.M.; SHAH, D. M. Amino acid biosynthesis inhibitors as herbicides. Annual Review of Biochemistry, v.57, n.4, p.627-663, 1988.

KLEIER, D.A. Phloem mobility of xenobiotics. I. Mathematical model unifying the weak acid and intermediate permeability theories. Plant Physiology, v.86, n.3, p.803-810, 1988.

KÖCHER, H. Influence of the light factor on physiological effects of the herbicide Hoe 39866. Aspects of Applied Biology, v.4, n.4, p.227-234, 1983.

KRIEG, L.C. et al. Growth, ammonia accumulation and glutamine synthetase activity in alfafa (Medicago sativa L.) shoots and cells treated with phosphinothricin. Plant Cell Reports, v.9, n.2, p.80-83, 1990.

KRUCKBERG, A.L. et al. Reduced activity mutants of phosphoglucose isomerase in the chloroplast and cytosol of Clarkia xantiana. Biochemistry Journal, v.261, n.1, p.457-467, 1989.

KUMADA, Y. et al. Evolution of the glutamine synthetase gene, one of the oldest existing and functioning genes. PNAS, v.90, n.7, p.30093013, 1993.

LEA, P.; RIDLEY, S.M. Glutamine synthetase and its inhibitors. In: DODGE, A.D. (ed.) Herbicides and Plant Metabolism. Cambridge: University Press. p.137-170, 1989.

LEA, P.J. Nitrogen metabolism. In: LEA, P.J.; LEEGOOD, R.C. (Eds). Plant Biochemistry and Molecular Biology. New York: Wiley. p.155-180, 1993. 
LEA, P.J. The inhibition of ammonia assimilation: a mechanism of herbicide action. In: BAKER, N.R.; PERCIVAL, M. P. (eds.). Herbicides. New York/Amsterdan: Elsevier. p.267-297, 1991.

LEE, L.J.; NGIM, J.A first report of glyphosateresistant goosegrass (Eleusine indica (L.) Gaertn.) in Malaysia. Pest Management Science, v.56, n.4, p.336-339, 2000.

LEGLEITER, T. R. et al. Glyphosate-resistant waterhemp (Amaranthus rudis) control and economic returns with herbicide programs in soybean. Weed Technology, v. 23, p. 54-61, 2009.

LOGUSCH, E.W. et al. Inhibition of plant glutamine synthetases by substituted phosphinothricins. Plant Physiology, v.95, n.4, p.1057-1062, 1991.

MANDERSCHEID, R.; WILD, A. Studies on the mechanism of inhibition by phosphinothricin of glutamine synthetase isolated from Triticum aestivum L. Journal of Plant Physiology, v.123, n.2, p.135-142, 1986.

MARSHALL， G.; KIRKWOOD， R.C.; LEACH, L.E. Comparative studies on graminicide-resistant and susceptible biotypes of Eleusine indica. Weed Research, v.36, n.3, p.177-185, 1993.

MASCHHOFF, J.R.; HART, S.E.; BALDWIN, J.L. Effect of ammonium sulfate on the efficacy, absorption, and translocation of glufosinate. Weed Science, v.48, n.1, p.2-6, 2000.

MCNALLY, S.F. et al. Glutamine synthetase of higher plants. Plant Physiology, v.72, n.1, p.2225, 1993.

MCWORTER, C.G. Translocation of 14Cglyphosate in soybean (Glycine max) and johnsongrass (Sorghum halepense). Weed Science, v.28, n.1, p.113-118, 1980.

MEEK, T.D.; VILLAFRANCA, J.J. Kinect mechanism of Escherichia coli glutamine synthetase. Biochemistry, v.19, n.1, p.55135519, 1980.

MELO, M.S.C. et al. Alternativas de controle químico de capim-amargoso (Digitaria insularis) resistente ao glyphosate. Revista Brasileira de Herbicidas, v.11, n.2, p.195-203, 2012.

MOREIRA, M.S. et al. Herbicidas alternativos para controle de biótipos de Conyza bonariensis e C. canadensis resistentes ao glyphosate. Planta Daninha, v.28, n.1, p.167-175, 2010.

MOREIRA, M.S. et al. Resistência de Conyza canadensis e Conyza bonariensis ao herbicida glyphosate. Planta Daninha, v.25, n.1, p.157164, 2007.

MUELLER, T.C. et al. Proactive versus reactive management of glyphosate-resistant or tolerant weeds. Weed Technology, v.19, n.1, p.924933, 2005.

MURAKAMI, T. et al. The bialaphos biosynthetic genes of Streptomyces hygroscopicus: molecular cloning and characterization of the gene cluster. Molecular Genetics and Genomics, v.205, n.3, p.42-50, 1986.

NALEWAJA, J.D.; WOZNICA, Z. Environment and chlorsulfuron phytotoxicicy. Weed Science, v.13, n.2, p.632-635, 1985.

NICOLAI, M. et al. Avaliação da praticabilidade agronômica dos herbicidas amônio-glufosinato e glyphosate em algodão Glytol (FM980GLT E FMT982GL) quanto a seletividade a cultura e controle de plantas daninhas. In: XXIX Congresso Brasileiro da Ciência das Plantas Daninhas, 2014, Gramado, RS. A Ciência das Plantas Daninhas em Clima de Mudanças. Resumos. SBCPD, 2014b.

NICOLAI, M. et al. Avaliação da praticabilidade agronômica dos herbicidas amônio-glufosinato e glyphosate em algodão Glytol LibertyLink quanto a seletividade a cultura e controle de plantas daninhas. In: 
Congresso Brasileiro de Algodão, IX, Brasília (DF), Resumos. ABRAPA: 2014a.

NORSWORTHY, J.K. et al. Reducing the risks of herbicide resistance: best management practices and recommendations. Weed Science, v.60, n.4, p.31-62, 2012.

PEREZ-JONES, A. et al. Identification of glyphosate-resistant Italian Ryegrass (Lolium multiflorum) in Oregon. Weed Science, v.53, n.3, p.775-779, 2005.

PLINE, W.A.; WU, J.; HATZIOS, K.K. Absorption, translocation, and metabolism of glufosinate in five weed species as influenced by ammonium sulfate and pelargonic acid. Weed Science, v.47, n.3, p.636-643, 1999.

POWLES, S.B.; YU, Q. Evolution in action: plants resistant to herbicides. Annual Review of Plant Biology, Palo Alto, v.61, n.4, p.317-347, 2010.

READE, J. P. H.; COBB, A. H. Herbicides: modes of action and metabolism. In: Naylor, $\mathrm{R}$ E. L. Weed management handbook. Oxford: Blackwell Science. 2002. p.134-170.

RUHLAND, M.; ENGELHARDT, G.; PAWLIZKI, K. Distribuition and metabolism of D/L-, L- and D-glufosinate in transgenic, glufosinate tolerant crops of maize (Zea mays $\mathrm{L}$ ssp. mays) and oilseed rape (Brassica napus L. var. vapus). Pest Management Sciences, v.60, n.1, p.691-696, 2004.

SANTOS, G. et al. Buva com resistência múltipla a herbicidas é identificada como Conyza sumatrensis no Paraná. Informe Técnico PGA - Universidade Estadual de Maringá. Maringá, PR, v.1, n.1, p.1-3, 2012.

SAUER, H.; WILD, A.; RÜHLE, W. The effect of phosphinotricin (glufosinate) on photosynthesis. II. The causes of inhibition of cell photosynthesis. Verlag der Zeitschrift für Naturforschung, v.42, n.3, p.270-278, 1987.

SELLERS, B.A.; SMEDA, R.J.; LI, J. Glutamine synthetase activity and ammonium accumulation in influenced by time of glufosinate application. Pesticide Biochemistry and Physiology, v.78, v.3, p.920, 2004.

SENG, C.T. et al. Initial report of glufosinate and paraquat multiple resistance traht evolved in a biotype of goosegrass (Eleusine indica) in Malaysia. Weed Biology and Management, v.10, n.1, p.229-233, 2010b.

SENG, C.T. et al. Initial report of glufosinate and paraquat multiple resistance that evolved in a biotype of goosegrass (Eleusine indica) in Malaysia. Weed Biology Management, v.10, n.3, p.229-233, 2010a.

SHELP, B.J.; SWANTON, C.J.; HALL, J.C. Glufosinate (phosphinothricin) mobility in young soybean shoots. Journal of Plant Physiology, v.139, n.1, p.626-628, 1992.

SKORA-NETO, F.; COBLE, H.; CORBIN, F. Absorption, translocation and metabolism of 14C-glufosinate in Xantium strumarium, Commelina diffusa, and Ipomoea purpurea. Weed Science, v.48, n.2, p.171-175, 2000.

STECKEL, G.J.; HART, S.E.; WAX, L.M. Absorption and translocation of glufosinate on four weed species. Weed Science, v.45, n.3, p.378-381, 1997.

STRAUCH, E.; WOHLLENBEN, W.; PÜHLER, A. Cloning of the phosphinothricin$\mathrm{N}$-acetyl-transferase gene from Streptomyces viridochromogenes Tü 494 and its expression in Streptomyces lividans and Escherichia coli. Gene, v.63, n.1, p.65-74, 1988.

TACHIBANA, K. et al. Accumulation of ammonia in plants treated with bialaphos. Journal of Pesticide Science, v.11, n.1, p.3337, 1986a.

TASHIBANA, K. et al. Inhibition of glutamine synthetase and quantitative changes of free acids in shoots of bialaphos treated Japanese barnyard millet. Journal of Pest Science, v.11, n.3, p.27-31, $1986 b$. 
ULLRICH, W.R.; ULLRICH-EBERIUS, C.I.; KOCHER, H. Uptake of glufosinate and contaminant membrane potential changes in Lemma gibba G1. Pesticide Biochemistry and Physiology, v.37, n.1, p.1-11, 1990.

UNNO, H. et al. Atomic structure of plant glutamine synthetase. The Journal of Biological Chemistry, v.281, n.1, p.2928729296, 2006.

VARGAS, L. et al. Conyza bonariensis biotypes resistant to the glyphosate in Southern Brazil. Planta Daninha, v.25, n.3, p.573-578, 2007.

VARGAS, L. et al. Identification of glyphosateresistant ryegrass (Lolium multiflorum) biotypes in apple orchards. Planta Daninha, v.22, n.1, p.617-622, 2004.

VASIL, I.K. Phosphinothricin-resistant crops. In: Duke, S. O. (ed.). Herbicide resistant crops. Boca Raton: CRC Press, p.85-91, 1996.

VAUGHN, K.C.; DUKE, S.O. Biochemical basis of herbicide resistance. Chemistry of Plant Protection, v.7, n.1, p.141-169, 1991.

VAUGHN, K.C.; VAUGHAN, M.A.; GOSSETT, B.J. A biotype of Goosegrass (Eleusine indica) with an intermediate level of dinitroaniline herbicide resistance. Weed Technology, v.4, n.3, p.157-162, 1990.

VIDAL, R.A. et al. Resistência de Eleusine indica aos inibidores de ACCase. Planta Daninha, v.24, n.1, p.163-171, 2006.

WEHRMANN, A. et al. The similarities of bar and pat get products make them equally applicable for plant engineer. National Biotechnology, v.14, n.1, p.1274-1278, 1996.

WILD, R.; MANDERSCHEID, R. The effect of phosphinothricin on the assimilation of ammonia in plants. Verlag der Zeitschrift für Naturforschung, v.39, n.3, p.500-504, 1984.

WOHLLEBEN, W. et al. Nucleotide sequence of the phosphinothricin N-Acetyltransferase gene from Streptomyces viridochromoenes
Tü494 and its expression in Nicotina tabacum. Gene, v.70, n.3, p.25-27, 1988.

WYCHEN, L.R.V. et al. Efficacy and crop response to glufosinate-based weed management in PAT-transformed corn (Zea mays). Weed Technology, v.13, n.1, p.104-111, 1999.

YAMASHITA, M.M. et al. Refined atomic modelo $\mathrm{f}$ glutamine synthetase at $3.5 \AA$ resolution. The journal of Biological Chemistry, v.26, n.4, p.17681-17690, 1989.

ZEIGLER, C.; WILD, A. The effect of bialaphos on ammonium-assimilation and photosynthesis. II. Effects on photosynthesis and photorespiration. Verlag der Zeitschrift für Naturforschung, v.44, n.3, p.103-108, 1989. 